\title{
The Doctoral Research of Acharya Prafulla Chandra Ray
}

\author{
Animesh Chakravorty*
}

(Received 22 April 2015)

\begin{abstract}
The ideas, methods and results concerning the title research (1885-1887) are examined. The impact of latter developments in structural chemistry on the meaning of the work is scrutinized. Double sulfates incorporating monovalent $(\mathrm{Mm})$ and bivalent $(\mathrm{Mb})$ metals, $\mathrm{Mm}_{2} \mathrm{SO}_{4} \cdot \mathrm{MbSO}_{4} \cdot 6 \mathrm{H}_{2} \mathrm{O}$, $\mathbf{1}$, had been known for long but the forces binding the two sulfates together in $\mathbf{1}$ were not understood. There were also a few controversial reports about double double sulfates where two type $\mathbf{1}$ salts differing in $\mathrm{Mb}$ (say $\mathrm{Mb}$ and $\mathrm{Mb}^{\prime}$ ) combined in 1:1 ratio giving new entities. This prompted Prafulla Chandra to engage in search, synthesis and characterization work to clarify the doubts in the area. He succeeded in isolating double double sulfates the combining proportion being variable (x:y) and not 1:1 ( $\mathrm{x}$ and $\mathrm{y}$ are integers that could vary from system to system). Decades later it was revealed that all type $\mathbf{1}$ salts strictly belong to the same structural type where ions $\left(\mathrm{Mm}^{+}, \mathrm{Mb}^{2+}\right.$ and $\left.\mathrm{SO}_{4}{ }^{2-}\right)$ and water molecules are held tightly into a unique three-dimensional lattice via coordination and hydrogen bonding networks ( no discrete metal sulfate molecules are present). Two such salts with different $\mathrm{Mb}$ forms solid solutions freely in any proportion with random distribution of $\mathrm{Mb}$ and $\mathrm{Mb}^{\prime}$ in the lattice. The double double sulfates reported by Prafulla Chandra and others could thus only be solid solutions or mixtures thereof but not discrete compounds. Historically this reinterpretation is but one example of the traverse of structural inorganic chemistry from a period of guesswork to one of informed visualization made possible by the advent of theories and physical tools.
\end{abstract}

Key words: Coordination, Double sulfates, Double double sulfates, Isomorphism, Hydrogen bonding network, Solid solution

\section{INTRODUCTION}

Prafulla Chandra's interest in chemistry was first aroused by Alexander Pedler's fascinating lectures and demonstrations during the FA course (1879-81) in Presidency College. His mind thus ignited, Prafulla Chandra a young man of small stature (Fig.1), had dreams of doing big science and the starting point had to be higher studies in Britain. And so it was when he joined at the age of 21 the B.Sc. course in Edinburgh University, Scotland after winning the Gilchrist Scholarship (1882). He was awarded the B.Sc. degree in 1885 and he knew by then that he was born for chemistry and the immediate next step would be doctoral work. Greater details of these events and a cursory description of his doctoral work have been chronicled by us earlier in this journal (Chakravorty, 2014, p.361). The purpose of this article is to describe and critically examine the content of his doctoral research (18851887) in the context of

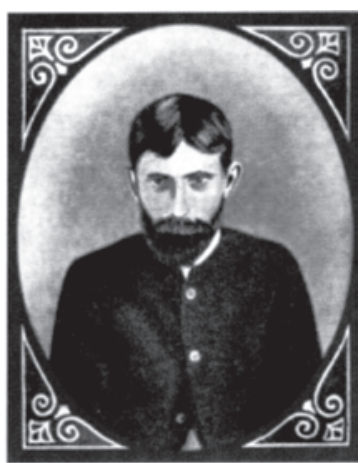

Fig. 1. Prafulla Chandra in his early youth his own times as well as of later times after structural chemistry had matured. It represents a good example of the traverse of inorganic research

\footnotetext{
* Department of Inorganic Chemistry, Indian Association for the Cultivation of Science, Kolkata 700032, Email: animeshc31@gmail.com
} 
from an age of guessing and groping to one of enlightened accounting.

Before proceeding further, we note that after returning back to Calcutta, Prafulla Chandra's research ideas moved far away from those in his doctoral work. During his tenure in Presidency College (1889-1916) he primarily explored the then little known chemistry of inorganic nitrites. And then he moved on to sulfur compounds and their complexes after he shifted to the University College of Science (1916-1936). His many discoveries over the time and their later impacts have been documented elsewhere (Chakravorty, 2014, p.1205, 2001; 2015, p.9).

\section{SPADEWORK}

In Prafulla Chandra's B.Sc. class the chemistry lectures were delivered by the renowned organic chemist Alexander Crum Brown (Professor and Head of the Department) — an erudite man with interests spreading much beyond chemistry. The B.Sc. practical work was, however, looked after by very able demonstrators like Dr. John Gibson who had been trained in the famed laboratory of Robert Bunsen at Heidelberg. Prafulla Chandra was much benefited from Gibson's teaching and tips on laboratory manipulations and methods of chemical analyses.

For the doctorate degree it was necessary for Prafulla Chandra to submit a thesis based on original work on a chemical problem of his own.
He spent much time in the library to study original chemical literature in English, French and German. With his deep interest in practical laboratory work as noted above, he searched for a research problem that will have an ample component of experimental work involving synthesis and analysis of interesting new groups of compounds possibly defining some unifying chemical principle. But to put the matter in proper perspective it is imperative to examine the state of chemistry of those times in the first place.

\section{State of Chemistry in around 1885}

The foundations of modern chemistry were laid virtually entirely by European chemists. The activity started peaking around mid-eighteenth century and continued through nineteenth century. The position in mid-1880's is briefly summarized in Table 1 and some further elaboration follows.

The central concept of 'combining power' of atoms also called atomicity (meaning valency: $\mathrm{H}=1, \mathrm{O}=2, \mathrm{~N}=3, \mathrm{C}=4$ ) was concretely proposed by E. Frankland (1825-1899), the British organic chemist who also invented organometallic chemistry. F. A. Kekule (1829-1896) in Germany propounded the theory of organic structures based on carbon tetravalence vis-à-vis carbon-carbon chains and rings. Other contributors in the area include E. Erlenmeyer (1825-1909), A. M. Butlerov (1828-1886), A. S. Couper (1831-1892) and A. Crum Brown (1832-1922). The Dutch chemistry genius J. H. van’t Hoff (1852-1911) and

Table 1. Summary of the state of chemistry around 1885

\begin{tabular}{|c|c|c|c|}
\hline & Branch & Major Developments & Primary Contributors \\
\hline 1. & Organic & $\begin{array}{l}\text { Atomicity (valency); } \\
\text { Carbon-carbon chains and rings; Carbon } \\
\text { stereochemistry }\end{array}$ & Frankland, Kekule, van’t Hoff, Le Bel \\
\hline 2. & Physical & $\begin{array}{l}\text { Ionic dissociation and equilibria; } \mathrm{H}^{+} / \mathrm{OH}^{-} \text {, } \\
\text { acid-base theory; } \\
\text { Law of dilution; } \\
\text { Reaction rates, activation energy and catalysis }\end{array}$ & Ostwald, van’t Hoff, Arrhenius \\
\hline 3. & Inorganic & Periodic law and table & Mendeleev \\
\hline
\end{tabular}


J. A. Le Bel (1847-1930) of France independently theorized the tetrahedral disposition of the four carbon valences to rationalize observed isomerism and other matters. Thus in the mid-1880's organic chemistry was progressing very well.

But it was not so for the other traditional branch: inorganic chemistry which concerned all elements including a few aspects of carbon too. In this inherently heterogeneous branch characterized by very many compound types, no single theory of inorganic structure was forthcoming or seemed immediately feasible. It simply remained as a dimly understood area very rich in number and types of compounds many of them very useful too. Then in 1866 young D. I. Mendeleev (1834-1907) became professor of general chemistry at the University of St. Petersburg (Chakravorty, 2000, May, p.2). General chemistry was then another name of inorganic chemistry. In organizing his course for students Mendeleev felt the urgent need for a suitable text book of inorganic chemistry. The result (1868) was Osovy Khimi or General Chemistry, better known in English as Principles of Chemistry. While writing the book Mendeleev tried to classify the elements in some rational manner. In his own words he wanted "to establish some sort of a system of elements" based on "numbers which can be determined accurately". He chose atomic weight as the characteristic number for this purpose. Thus in 1869 with the 63 elements then known Mendeleev invented the periodic law to classify elements, the first gigantic step in the pursuit of modern inorganic chemistry. The next such step would arrive only much later with A. Werner's (1866-1919) formulation of coordination theory (1893) enlightening the structure and geometry of complex metal compounds.

Lastly physical chemistry started emerging as a new member of the chemical science family only in the latter half of nineteenth century. The initial concerns included equilibria, rates and energetics of reactions etc. Thermodynamic principles provided some of the basic anchors. The three early pioneers of the field were W. Ostwald (1853-1932) of Germany (law of dilution, reaction velocities and catalysis), S. Arrhenius (1859-1921) of Sweden (theory of ionic dissociation, acid-base theory, Arrhenius equation) and J. H. van't Hoff of Denmark (principles of chemical kinetics, osmotic pressure).

\section{Choice of Area}

The newly emerging physical chemistry area had virtually no roots in British laboratories in Prafulla Chandra's time. Indeed one of his fellow students, James Walker who had taken a doctorate degree from Edinburgh in organic chemistry a few months earlier became interested in physical chemistry and proceeded to Germany to work with Ostwald. On his return he would succeed Crum Brown to lead the chemistry department at Edinburgh and thus giving an impetus to physical chemistry research in Edinburgh and elsewhere in UK. But all this happened much after Prafulla Chandra's time in Edinburgh.

Although Crum Brown was there, Prafulla Chandra was not much interested to work in organic chemistry. A student loving his subject would often intuitively feel within himself the direction he should follow. This happened to Prafulla Chandra who chose his research area and problem relatively effortlessly. We have seen above that the general area of inorganic chemistry was then rather dimly lighted but this disadvantage was also an opportunity in disguise for an ardent seeker like Prafulla Chandra interested in experiments.

After searching the literature, the specific area of research chosen concerned metal sulfates often called vitriols (salts of oil of vitriol i.e., sulfuric acid) in olden times (Karpenko, 2002, p.997). Of these some like $\mathrm{FeSO}_{4} \cdot 7 \mathrm{H}_{2} \mathrm{O}$, $\mathrm{CuSO}_{4} .5 \mathrm{H}_{2} \mathrm{O}$ and $\mathrm{ZnSO}_{4} .7 \mathrm{H}_{2} \mathrm{O}$ - green, blue and 
white vitriols respectively - have been known from antiquity as natural minerals or artificial compounds. It had also been definitely known from 1850 if not earlier that sulfates of bivalent metals readily combine with others of monovalent metals (or $\mathrm{NH}_{4}^{+}$) in 1:1 ratio to afford characteristic double sulfates which were chemical entities distinct from the constituent sulfates.

Some of these are known to occur as minerals in Nature (Bosi, 2009, p.74). Representative examples are $\mathrm{K}_{2} \mathrm{SO}_{4} \cdot \mathrm{MgSO}_{4} \cdot 6 \mathrm{H}_{2} \mathrm{O}$ or $\mathrm{K}_{2} \mathrm{Mg}\left(\mathrm{SO}_{4}\right)_{2} \cdot 6 \mathrm{H}_{2} \mathrm{O}, \mathrm{K}_{2} \mathrm{Cu}\left(\mathrm{SO}_{4}\right)_{2} \cdot 6 \mathrm{H}_{2} \mathrm{O}$, $\left(\mathrm{NH}_{4}\right)_{2} \mathrm{Ni}\left(\mathrm{SO}_{4}\right)_{2} \cdot 6 \mathrm{H}_{2} \mathrm{O}$ and $\left(\mathrm{NH}_{4}\right)_{2} \mathrm{Fe}\left(\mathrm{SO}_{4}\right)_{2} \cdot 6 \mathrm{H}_{2} \mathrm{O}$. In mineralogy this class of minerals fall in the group picromerite or schönite. Such double sulfates have also been known to be readily synthesizable in the laboratory via cocrystallization of constituent sulfates. For example the German analytical chemist K. F. Mohr (1806-1879) so synthesized light green $\left(\mathrm{NH}_{4}\right)_{2} \mathrm{Fe}\left(\mathrm{SO}_{4}\right)_{2} \cdot 6 \mathrm{H}_{2} \mathrm{O}$, the commonly used laboratory chemical called Mohr salt (same composition as the mineral called mohrite).

This class of double salts can be generally represented as in $\mathbf{1}$, where $\mathrm{Mm}$ and $\mathrm{Mb}$

$$
\begin{gathered}
\mathrm{Mm}_{2} \mathrm{SO}_{4} \cdot \mathrm{MbSO}_{4} \cdot \mathbf{6 \mathrm { H } _ { 2 } \mathrm { O }} \\
\mathrm{Mm}=\text { monovalent like } \mathrm{K}, \mathrm{NH}_{4} \\
\mathrm{Mb}=\text { bivalent like } \mathrm{Mg}, \mathrm{Fe}
\end{gathered}
$$

\section{1}

are respectively monovalent and bivalent metals. At the present time the list of type $\mathbf{1}$ salts include : $\mathrm{Mm}=\mathrm{K}, \mathrm{Rb}, \mathrm{Cs}, \mathrm{Tl}, \mathrm{NH}_{4}$ etc. and $\mathrm{Mb}=\mathrm{V}, \mathrm{Cr}$, $\mathrm{Mn}, \mathrm{Fe}, \mathrm{Co}, \mathrm{Ni}, \mathrm{Cu}, \mathrm{Zn}, \mathrm{Mg}, \mathrm{Cd}$. Some of these salts became known only after Prafulla Chandra's time. Tutton examined the trends of crystallographic parameters and certain other properties of a number of such salts for the first time during 1893-1896 (Tutton, 1893, p.337; 1896, p.344). Since then such salts are often called Tutton salts. Detailed X-ray structural works on $\mathbf{1}$ could be undertaken only decades later and these will be of critical value for assessment of Prafulla Chandra's doctoral work.

\section{Choice of Research Problem}

At that time little was known about the nature of affinity that holds the constituent sulfates and the water molecules in the double sulfates and chemists speculated and searched for even high order sulfates. Thus in 1855 Vohl wrote a long report claiming the isolation of numerous double double sulfates of compositional type 2 where $\mathrm{Mb}$ and $\mathrm{Mb}^{\prime}$ are two different bivalent metals (Vohl,1855, p.57). He also described a couple of triple double sulfates and a quadrupole double sulfate. It was conjectured that the double sulfate

\section{$\left[\mathrm{Mm}_{2} \mathrm{SO}_{4} \cdot \mathrm{MbSO}_{4} \cdot 6 \mathrm{H}_{2} \mathrm{O}\right]$. $\left[\mathrm{Mm}_{2} \mathrm{SO}_{4} \cdot \mathrm{Mb}^{\prime} \mathrm{SO}_{4} \cdot 6 \mathrm{H}_{2} \mathrm{O}\right]$}

\section{2}

$\mathrm{Mm}_{2} \mathrm{Mb}\left(\mathrm{SO}_{4}\right)_{2} \cdot 6 \mathrm{H}_{2} \mathrm{O}$ arose via substitution of one water molecule in $\mathrm{MbSO}_{4} \cdot 7 \mathrm{H}_{2} \mathrm{O}$ by $\mathrm{Mm}_{2} \mathrm{SO}_{4}$. Similarly the double double sulfate 2 was theorized to arise from an intermediary bivalentbivalent double sulfate $\mathrm{MbMb}\left(\mathrm{SO}_{4}\right)_{2} \cdot 14 \mathrm{H}_{2} \mathrm{O}$ via replacement of two water molecules by two $\mathrm{Mm}_{2} \mathrm{SO}_{4}$ units.

Prafulla Chandra decided to further explore the chemistry of double double sulfates as his doctoral research. He had noted that in 1850's there were other reports, besides that of Vohl claiming the formation of multiple double sulfates (Ray, 1888, p.267). Prafulla Chandra's interest was further augmented by a report by Aston and Pickering appearing at that time questioning the existence of Vohl's multiple doubled sulfates (Aston,1886, p.123). These authors had attempted to prepare several of the reported salts by following the simple method employed by Vohl viz., mixing solutions of the constituent sulfates in the requisite proportions and leaving the mixture to evaporate spontaneously. The composition of the salts thus obtained did in no case corresponded to Vohl's results and the 
authors concluded that none of them can be regarded as definite chemical entities and made the cautious noting,

\begin{abstract}
"it is certainly with some diffidence that we venture to throw doubt on the surprisingly accurate analysis of 50 different salts published by Vohl and we are even unable to explain his results....the very methods employed by him have failed to yield us definite compounds."
\end{abstract}

It was also noted by the same authors as well as by Prafulla Chandra in his paper cited above that a report in 1877 had already raised similar doubts while trying to prepare one of Vohl's double double sulfates $\left(\mathrm{Mm}=\mathrm{K}, \mathrm{Mb}=\mathrm{Co}, \mathrm{Mb}^{\prime}=\right.$ Ni). Prafulla Chandra's considered opinion was that although these 'investigations certainly seemed to throw grave doubts on the trustworthiness of Vohl's early research ' the position was unclear and further work was called for.' He proceeded with his plan hoping to clarify matters and settle questions.

\section{Methods And Results}

A copy of Prafulla Chandra's D.Sc. thesis could not be accessed by this author either from University of Edinburgh or elsewhere. Fortunately the work is well documented as a published paper (Ray, 1888, p.267). The sulfates concerning him had $\mathrm{Mm}=\mathrm{K}, \mathrm{NH}_{4}$ and $\mathrm{Mb}, \mathrm{Mb}^{\prime}=\mathrm{Fe}, \mathrm{Co}, \mathrm{Ni}, \mathrm{Cu}$, $\mathrm{Zn}, \mathrm{Mg}, \mathrm{Cd}$. The methods of preparation of individual salts are given in detail in the paper.

Briefly stated, the preparation consisted of leaving a nearly saturated aqueous solution (made slightly acidic with sulfuric acid) of a mixture of the constituent sulfates taken in equivalent or nearly equivalent proportions to evaporate spontaneously in flat-bottomed dishes. Once crystallization started it proceeded well and after a time it more or less ceased. The crop was collected as a whole or in some cases in stages. After a long pause crystallization recommenced but the crop was often a heterogeneous mixture.
Prafulla Chandra's work was mainly concerned with the first crop either the whole or the stages where relevant. The crystals collected were dried and subjected to quantitative analysis (Mb and $\mathrm{Mb}^{\prime}$ only). Only about ten per cent of the combined weight of sulfates in solution was collected as crop(s).

The analytical data collected by him were found to fit well with a compositionally flexible double double sulfate formulation of type 3 where the relative proportions ( $\mathrm{x}: \mathrm{y}, \mathrm{x}$ and $\mathrm{y}$ small integers) of the individual double salts generally varied from system to system and often among different stages of collection of crystals for a given MmMbMb' system (see Table 2). The variation is remarkable but did not display any discernible pattern. Prafulla Chandra did not provide any cogent rationale for this outside simply noting certain qualitative factors like relative solubility of the constituent sulfates, small variations of concentration of individual sulfates, change in the relative concentration of constituent sulfates as crystallization progressed, variation of ambient temperature (no thermostat used) etc.

\section{$\mathrm{x}\left[\mathrm{Mm}_{2} \mathrm{SO}_{4} \cdot \mathrm{MbSO}_{4} \cdot 6 \mathrm{H}_{2} \mathrm{O}\right]$. $\mathrm{y}\left[\mathrm{Mm}_{2} \mathrm{SO}_{4} \cdot \mathrm{Mb}^{\prime} \mathrm{SO}_{4} \cdot 6 \mathrm{H}_{2} \mathrm{O}\right]$}

3

Table 2. Several double double sulfates reported by Prafulla Chandra as examples of his type $\mathbf{3}$ formulation

\begin{tabular}{|lccccc|}
\hline Salt & $\mathrm{x}$ & $\mathrm{Mb}$ & $\mathrm{y}$ & $\mathrm{Mb}^{\prime}$ & $\mathrm{Mm}$ \\
\hline 1. & 4 & $\mathrm{Fe}$ & 5 & $\mathrm{Cu}$ & $\mathrm{NH}_{4}$ \\
2. & 2 & $\mathrm{Fe}$ & 3 & $\mathrm{Cu}$ & $\mathrm{NH}_{4}$ \\
3. & 2 & $\mathrm{Fe}$ & 3 & $\mathrm{Mg}$ & $\mathrm{NH}_{4}$ \\
4. & 2 & $\mathrm{Fe}$ & 5 & $\mathrm{Zn}$ & $\mathrm{NH}_{4}$ \\
5. & 7 & $\mathrm{Fe}$ & 4 & $\mathrm{Mn}$ & $\mathrm{NH}_{4}$ \\
6. & 2 & $\mathrm{Fe}$ & 9 & $\mathrm{Ni}$ & $\mathrm{K}$ \\
7. & 5 & $\mathrm{Cu}$ & 4 & $\mathrm{Co}$ & $\mathrm{K}$ \\
8. & 9 & $\mathrm{Cu}$ & 2 & $\mathrm{Ni}$ & $\mathrm{K}$ \\
9. & 5 & $\mathrm{Cu}$ & 1 & $\mathrm{Mg}$ & $\mathrm{K}$ \\
10. & 12 & $\mathrm{Cu}$ & 1 & $\mathrm{Cd}$ & $\mathrm{NH}_{4}$ \\
11. & 1 & $\mathrm{Co}$ & 2 & $\mathrm{Ni}$ & $\mathrm{K}$ \\
12. & 9 & $\mathrm{Zn}$ & 2 & $\mathrm{Mn}$ & $\mathrm{NH}_{4}$ \\
\hline
\end{tabular}


He made observations such as, '.... slight changes in the various conditions under which the crystals are formed may have a determining influence upon the compositions of compounds separating out from solution...' and '.....difficulties in the way of discriminating between a homogeneous crystallized salt and a mixture consisting of two or more salts in variable proportions are undoubtedly great...' Such comments underline the doubts that must have concerned him. But he maintained that his work demonstrated that proceeding cautiously with the synthetic work definite double double sulfates (type 3) with variable but integral $x$ and $y$ can be obtained. He also asserted that Aston and Pickering failed to obtain definite compounds because the methods used by them necessarily brought about heterogeneous deposits.

Prafulla Chandra's D.Sc. thesis (1887) was entitled, “Conjugated Sulphates of CopperMagnesium Group. A Study of Isomorphous Mixtures and Molecular Combinations”. He took recognition of the isomorphous nature of the constituent sulfates and their ability to cocrystallize. He however firmly believed that the species of type $\mathbf{3}$ isolated by him (Table 2) were molecular combinations with integral $\mathrm{x}$ and $\mathrm{y}$ values as opposed to mere isomorphous mixtures. The large and random variations of $\mathrm{x}$ and $\mathrm{y}$ did not surprise him nor the experienced chemists around him including Crum Brown who specially appreciated the work and suggested possible future work on the limits of composition of solutions between which a given definite compound of type 3 separate out.

At that time little was known about the internal atomic level structure of crystals and there were few definitive guidelines to go by to interpret the significance of composition of multi-salt solids of the type under consideration beyond the mere formula experimentally derived. This situation continued for decades till X-ray structure determination tools arrived.
Before concluding this section we note an indirect outcome of historical importance from Prafulla Chandra's work. After D.Sc. the Hope Prize Scholarship was offered to him to continue his activities for a year. By then he had become passionately fond of chemistry. He was now required to help junior students with practical work in the laboratory. Hugh Marshall (1868-1913) was one such student and to test his analytical skill Prafulla Chandra gave him one of his KCoCu salts (Table 2). Marshall tried the electrolytic method of analysis and landed with the discovery of cobalt alum and perdisulfuric acid also called Marshall's acid. The rest is history and later Prafulla Chandra would write lovingly

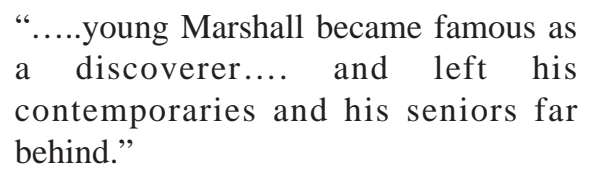

\section{Structure of Double Sulfates OF TYPE 1}

This became clear only after the X-ray diffraction methods could be applied to them. This started in early 1930's and took good shape by early 1960’s (Montgomery, 1964, p.1295). Many later studies of increasing accuracy have covered numerous salts. The entire family belongs to the monoclinic system (space group $P 2_{1 / \mathrm{c}}$ or equivalently $P 2_{1 / \mathrm{a}}$ ). Double sulfate formation is entirely a crystallographic phenomenon involving arrangement of the ions $\left(\mathrm{Mm}^{+}, \mathrm{Mb}^{2+}, \mathrm{SO}_{4}{ }^{2-}\right)$ and water molecules in the crystal lattice. In aqueous solution the structure disintegrates into a random distribution of hydrated ions.

The shapes of a few building entities in the crystal lattice are depicted in 4. Each $\mathrm{Mb}^{2+}$ ion in the crystal is bonded to the six water molecules (i.e., $\mathrm{Mb}^{2+}$ coordination number is 6 ) in an approximate octahedral fashion (4a, $\mathbf{4 b})$. The hydrogen atoms of each water molecule form $\mathrm{O}$ $\mathrm{H}-\mathrm{O}$ hydrogen bonds with oxygen atoms of tetrahedral sulfate ions (4c) thus promoting a 

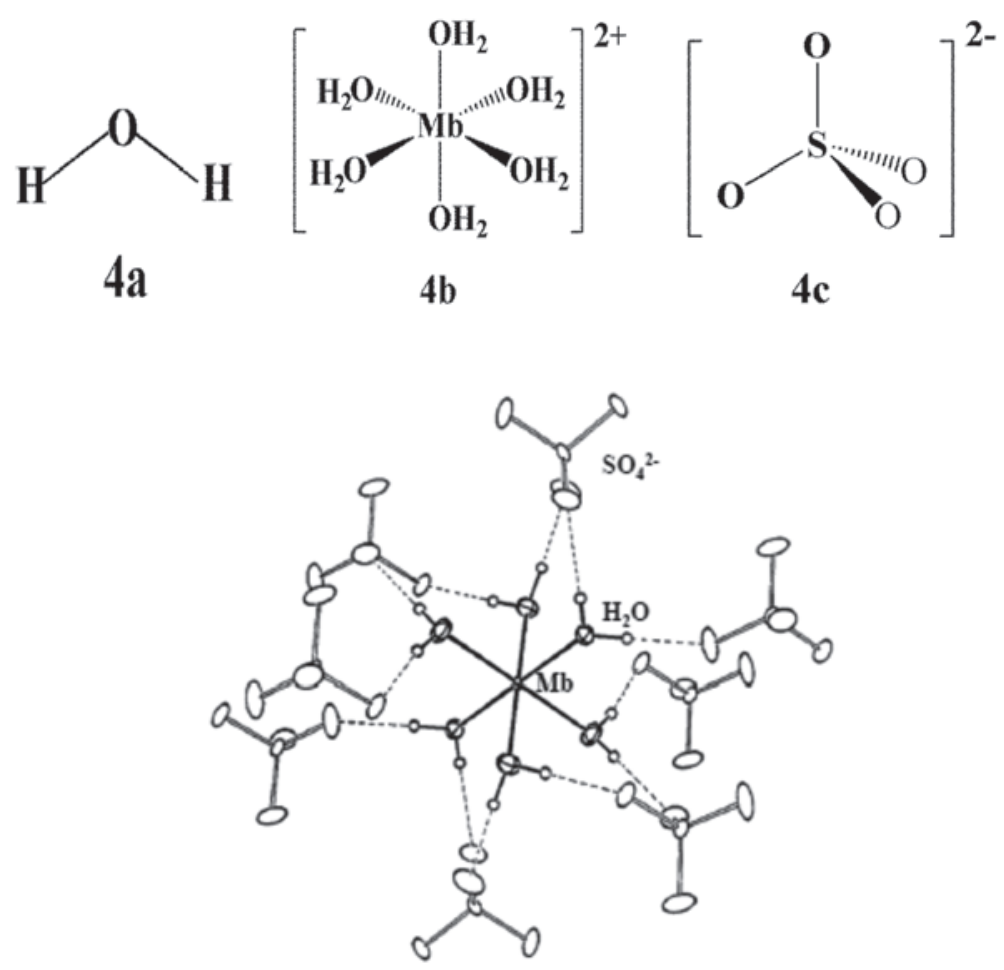

Fig. 2. The octahedral binding (coordination) of water molecules to the bivalent metal and water- sulfate hydrogen bonding network (dotted lines) in the crystal lattice of type $\mathbf{1}$ double sulfates

stable network (Fig. 2) that ensures the persistence of the same structural type across the whole series (Cotton, 1993, p.4861). The $\mathrm{Mm}^{+}$ion binds to the above $\mathrm{Mb}^{2+}-\mathrm{H}_{2} \mathrm{O}-\mathrm{SO}_{4}{ }^{2-}$ core. In the ammonium salts $\left(\mathrm{Mm}^{+}=\mathrm{NH}_{4}^{+}\right)$, the tetrahedral ammonium ions form $\mathrm{N}-\mathrm{H}-\mathrm{O}$ hydrogen bonds to sulfate oxygen atoms. On the other hand in the potassium salts, the $\mathrm{K}^{+}$ions are bonded to six sulfate oxygen atoms and two water oxygen atoms $\left(\mathrm{K}^{+}\right.$ coordination number 8 ). Thus the sulfate ions and water molecules act as bridges between $\mathrm{Mb}^{+}$and $\mathrm{K}^{+}$. Around each $\mathrm{K}^{+}$ion the eight bonded neighbours are arranged in an approximate bicapped trigonal prismatic geometry. Thus the monocations provide further stabilization of the structure via supportive network of $\mathrm{N}-\mathrm{H}-\mathrm{O}$ hydrogen bonding or $\mathrm{Mb}-\mathrm{O}$ bonding (coordination). More details about $\mathrm{NH}_{4}{ }^{+}$and $\mathrm{K}^{+}$ binding in type $\mathbf{1}$ salts including good structural drawings can be found respectively in the papers (Bosi, 2009, p.74) and (Araya,1993, p.4853).

\section{Solid Solutions}

Apart from being generally isostructural (same space group), two salts differing in Mb are never far from being isometric (same cell dimensions). They thus represent model examples of isomorphism and form solid solutions ('mixed crystals') of type $\mathrm{Mm}_{2} \mathrm{Mb}_{\mathrm{p}} \mathrm{Mb}^{\prime}{ }_{1-\mathrm{p}}\left(\mathrm{SO}_{4}\right)_{2} \cdot 6 \mathrm{H}_{2} \mathrm{O}$ where $\mathrm{p}$ can be varied more or less freely in the domain 1 to 0 by controlling the composition of the crystallizing solution and other conditions. Without control one may end up in getting a mixture of solid solutions differing in p values. A noteworthy instance of definitive solid solution studies concerns the $\mathrm{Mb}=\mathrm{Cr}$ and $\mathrm{Mb}^{\prime}=\mathrm{Zn}$ system with $\mathrm{A}=\mathrm{NH}_{4}$. In $\left(\mathrm{NH}_{4}\right)_{2} \mathrm{Zn}\left(\mathrm{SO}_{4}\right)_{2} 6 \mathrm{H}_{2} \mathrm{O}$, the $\mathrm{Zn}^{\mathrm{II}}-$ $\mathrm{O}$ coordination geometry is nearly ideally octahedral whereas in the $\mathrm{Cr}^{\mathrm{II}}$ salt the corresponding geometry is considerably distorted due to strong Jahn-Teller activity of $\mathrm{Cr}^{\mathrm{II}}$ which also imposes certain difference in the details of 
the hydrogen bonding network. Even then the two salts form solid solutions freely. Several carefully crystallized members of $\left(\mathrm{NH}_{4}\right)_{2} \mathrm{Cr}_{\mathrm{p}} \mathrm{Zn}_{1-\mathrm{p}}$ $\left(\mathrm{SO}_{4}\right)_{2} \cdot 6 \mathrm{H}_{2} \mathrm{O}$ in the p range 0.07 to 0.93 as well as the end members ( $\mathrm{p}=1$ and 0 ) were all found to crystallize in the same space group with very similar unit cell dimensions. The gross internal structure of the lattice was the same but for relatively minor distortions and adjustments. The $\mathrm{Cr}^{2+}$ and $\mathrm{Zn}^{2+}$ ions are distributed randomly in the lattice (Araya, 1993, p.4853). A similar VZn system $\left(\mathrm{A}=\mathrm{NH}_{4}\right)$ with $\mathrm{p}=0.45$ has also been structurally characterized (here $\mathrm{V}^{\mathrm{II}}$ is Jahn-Teller active) (Deeth, 1988, p.1289).

\section{No Double Double Sulfates}

Crystal structural works of which the above examples are representative have revealed the unique stability of the structural pattern of type 1 double sulfates fortified by tight coordination and hydrogen bonding networks. This ensures that salts differing in the bivalent metal form solid solutions more or less freely. For such mixtures there is no driving force for the formation of any new phase having a structural form different from the above type. The double double sulfates so formulated by early workers like Vohl, Prafulla Chandra and others on the basis of chemical composition alone were undoubtedly solid solutions or mixtures thereof $(0 \leq \mathrm{p} \leq 1)$.

Using the logic in the reverse mode the authentic solid solutions noted in the previous section could have been formulated as double double sulfates. For example the $\mathrm{V}_{0.45} \mathrm{Zn}_{0.55}$ system would translate to Prafulla Chandra's type $\mathbf{3}$ salt with $\mathrm{x}=9, \mathrm{y}=11$. And $\mathrm{Cr}_{0.48} \mathrm{Zn}_{0.52}$ system to $\mathbf{3}$ ( $\mathrm{x}$ $=12, \mathrm{y}=13$ ) or allowing a higher degree of analytical error as $\mathbf{3}(\mathrm{x}=\mathrm{y}=1)$ which is a Vohl type formulation. But such formulations are meaningless as the substances are uniform solid solutions and not molecular compounds of two entities.
But for Vohl in 1855 and Prafulla Chandra in 1887 when nothing was known about the internal structure of double sulfates, when chemical composition was virtually the only tool available for scrutiny, the proposals of double double sulfates $(2,3)$ were not very irrational. Prafulla Chandra's proposal with variable $\mathrm{x} / \mathrm{y}$ ratio was at least more realistic than Vohl's fixed $\mathrm{x} / \mathrm{y}=1$. But naturally all solid solution compositions would not fit to relatively small and integral values of $\mathrm{x}$ and $\mathrm{y}$ unless severe approximations are made. To restate, the truth that emerged after the many structural works is: solid solutions only and no double double sulfates of any kind. After failing to reproduce Vohl's compositions Aston and Pickering noted in their paper about what they could isolate: '...we can certainly not call them definite compounds, but substances more nearly resembling the product of crystallization of two isomorphous salts.” This stands close to the true situation as known today and remains the best guess of those times.

Decades later from the days in Edinburgh, Prafulla Chandra did revisit the field of double sulfates on a few occasions in Calcutta. He prepared analogues (with differences in the level of hydration) of $\mathbf{1}$ with $\mathrm{R}_{3} \mathrm{~S}^{+}$or $\mathrm{R}_{4} \mathrm{P}^{+}$as $\mathrm{Mm}^{+}$. More importantly around 1930 he deftly used the principle that $\mathrm{BeF}_{4}^{2-}, \mathrm{PO}_{3} \mathrm{~F}^{2-}$ and $\mathrm{SO}_{4}^{2-}$ being of similar size and having the same number (32) of valence electrons, should form isomorphous salts. Indeed he reported a series of such salts in Nature. Further details and references of the revisit can be found in our earlier article in this journal (already cited).

\section{Conclusion}

At Edinburgh Prafulla Chandra developed a liking for both laboratory work and inorganic chemistry during his B.Sc. days. Accordingly he chose to do his independent D.Sc. work (18851887) on a little understood topic that had much interest at that time viz., double salts, more 
specifically double sulfates. The particular problem he selected to investigate was to find out if two double sulfates of type 1 differing in the bivalent metal $\mathrm{Mb}$ would combine in definite integral proportions to yield a new molecular double double salt as reported by some previous workers but contradicted by others. After examining numerous $\mathrm{Mb}, \mathrm{Mb}^{\prime}$ combinations Prafulla Chandra concluded that molecular double double sulfates of type $\mathbf{3}$ with variable but integral $\mathrm{x}$ and $\mathrm{y}$ exist and can be isolated. Many decades later (1930 on) the internal structure of numerous type 1 salts and their solid solutions became known and it emerged that the bonding pattern in the crystal ensured that type 1 salts generally have the same structure with but minor variations. All reported molecular double double sulfates including those of Prafulla Chandra could only be solid solutions or mixtures thereof.

\section{ACKNowledgement}

Support received from Tata Chemicals Limited in the form of a Distinguished Emeritus Professorship (2014-2016) and from IACS Emeritus Professorship are gratefully acknowledged.

\section{AbBreviations}

AC - Acta Crystallographica

AM - American Mineralogist

AJC - Australian Journal of Chemistry

CL - Chemicke Listy

IJHS - Indian Journal of History of Science

IC - Inorganic Chemistry

JCST - Journal of the Chemical Society, Transaction

JICS - Journal of International Chemical Society

JLA - Justus Liebig's Annalen der Chemie

PRSE - Proceedings of Royal Society of Edinburgh

RES - Resonance

\section{BIBLIOGRAPHY}

Araya, M. A., Cotton, F. A., Daniels, L. M. Falvello, L. R. \& Murillo, C. A. Solid Solutions of a Jahn-Teller Compound in an undistorted host. 3. The Chromium/ Zinc Tutton System. IC, 32 (1993): 4853-4860.
Aston, E \& Pickering, S. U. On Multiple Sulphates. JCST, 49 (1886): 123-130.

Bosi, F., Belardi, G. \& Ballirano, P. Structural Features of Tutton's Salts $\mathrm{K}_{2}\left[\mathrm{M}\left(\mathrm{H}_{2} \mathrm{O}\right)_{6}\right]\left(\mathrm{SO}_{4}\right)_{2}$, with $\mathrm{M}=\mathrm{Mg}$, Fe, Co, Ni, Cu and Zn. AM, 94 (2009): 74-82.

Chakravorty, A. Dmitrii Ivanovich Mendeleev. RES, May (2000): 2-3.

Chakravorty, A. The Chemical Researches of Acharya Prafulla Chandra Ray. IJHS, 49 (2014): 361-370.

Chakravorty, A. Chemistry of Nitrites: Contributions of P. C. Rây and Some Later Developments. JICS, 91 (2014): 1205-1212.

Chakravorty, A. Sulfur Ligand Chemistry of Mercury and Gold : Contributions of P. C. Ray and Related Later Developments. JICS, 91 (2014): 2001-2007.

Chakravorty, A. Chemistry of Platinum and Iridium Complexes of Thioethers : Contributions of P.C. Ray and Related Later Developments. JICS, 92 (2015): 914

Cotton, F. A., Daniels, L. M., Murillo, C. A. \& Quesada, J. F. Hexaaqua Dipositive Ions of the First Transition Series ; New and Accurate Structures; Expected and Unexpected Trends. IC, 32 (1993): 4861-4867.

Deeth, R. J., Figgis, B. N., Forsyth, J. B., Kucharski, E. S. \& Reynolds, P. A. AJC, 41 (1988): 1289-1294.

Karpenko, V. \& Norris, J. A. Vitriol in the History of Chemistry. $C L$, 96(2002):997-1005.

Montgomery, H. \& Lingafelter, E. C. Crystal Structures of Tutton's Salts: I. Zinc Ammonium Sulfate Hexahydate: AC, 17 (1964): 1295-1299 (references to earlier crystallographic works can be found in this reference).

Ray, P. C. On the Conjugated Sulphates of the CopperMagnesium Group. PRSE, (1888): 267-283.

Tutton, A. E. Connection Between the Atomic weight of Contained Metals, and the Magnitude of the Angles of Crystals of Isomorphous Series. JCST, 63(1893): 337-423.

Tutton, A. E. Connection Between the Atomic Weight of Contained Metals and the Crystallographic Characters of Isomorpous Salts. JCST, 69 (1896):344-495.

Vohl, H. Ueber die Gepaarten Schwefelsauren Doppelsalze der Magnesiagruppe 'und Ihere Paarungen unter Einander. JLA, 94 (1855): 57-77. 